\title{
Perspectives on the Design and Evaluation of Adaptive Web Based Learning Environments
}

\author{
Fethi A. Inan \\ Texas Tech University, United States \\ Raymond Flores \\ Texas Tech University, United States \\ Michael M. Grant \\ The University of Memphis, United States
}

\begin{abstract}
Adaptive Web-Based Learning Environments (A-WBLEs) provide mechanisms to individualize instruction (e.g., content, interface, strategies, and assessment) for learners based on their individual differences. In this paper, various adaptive methods influencing the design of AWBLEs are explained and how these methods aim to address individual differences is discussed. Empirical evaluations of adaptive systems are synthesized and four levels for categorizing AWBLEs are created to provide a guideline for future design and development of A-WBLEs .
\end{abstract}

Keywords: Adaptive Web-based learning environments; Individual differences; Online learning; Individualized instruction; Adaptive hypermedia

\section{Introduction}

Learning via interactive, virtual web-based communities and environments is gaining popularity every day as the number of web-supported or web-based courses in training, colleges, and K-12 has and continues to increase significantly (Allen \& Seman, 2004, 2008; Picciano, 2001; Setzer \& Lewis, 2005). Web based learning environments have increased in popularity because they allow for teaching and learning to occur independent of place and time (Gunawardena \& Mclsaac, 2003; Moore \& Kearsley, 1996); and more importantly because they promise many advantages by allowing for a more interactive, personalized, and independent learning experience (Dabbagh \& Bannan-Ritland, 2005; Gunawardena \& Mclsaac, 2003; Khan, 1997; Song, Singleton, Hill \& Koh, 2004). Being flexible, interactive, and resourcerich in nature, web based learning environments have great potential to support studentcentered learning (Hannafin, Hill, \& Land, 1997; Hill \& Hannafin, 2001; Inan \& Lowther, 2007). Unfortunately, although web based learning environments have unlimited prospects for educational use, they do however have drawbacks-- namely the numerous implementation problems and challenges that are confronted when it comes to meeting all students' instructional needs (Chen, \& Paul, 2003; De Bra, 2000; Inan \& Grant, 2006; Song, Singleton, Hill $\&$ Koh, 2004). The source of these problems and challenges has been primarily attributed to 
the nature of the non-linear attributes of the web based learning environments, low quality of online instruction, and diverse learner profiles and characteristics.

The environmental challenges and factors affecting student learning in the online environment is largely due to the design of Web-based instruction in which designers or instructors provide optimal instructional strategies, interface, and content presentation; and expect all learners to fit into the system. This expectation is usually multiplied by the actions of inexperienced instructors or designers who fail to - provide individualized feedback, apply appropriate instructional strategies, create sufficient interaction, develop high quality content, build a learning community with social integration, and /or fail to monitor student progress ( $O^{\prime} B$ rien \&Renner, 2002; Saba, 2002; Schrum \& Benson, 2001; Song, Singleton, Hill \& Koh, 2004; Terry, 2001; Vonderwell, 2003; Zheng \& Smaldino, 2003).

Another major challenge of Web-based learning involves the task of accommodating students with differing profiles, expectations, prior experiences, and learning abilities (Picciano, 2001; Sikora \& Carroll, 2003). Adding to the complexity of this challenge is the fact that many learners cannot handle online course requirements and take control of their learning (Berge, 2002; Picciano, 2001; Saba, 2002). Furthermore, most online learners underestimate the time and effort required for online courses (Vergidis \& Panagiotakopoulos, 2002; Yukselturk \& Inan, 2006; Xenos \& Pierrakeas \& Pintelas, 2002), fail to incorporate effective learning and task strategies (Saba, 2002; Dutton, Dutton, \& Perry, 2002), have ill-defined educational goals and/or have limited motivation (Parker, 1995; Yukselturk \& Inan, 2006). Unfortunately, these self-regulated learning skills, which many students lack, are critical for success and satisfaction in web-based learning environments (McGrath, 1998; Berge, 2002).

\section{Adaptive Web Based Learning Environments}

Adaptive Web-Based Learning Environments (A-WBLEs) are a form of online instruction which attempt to address many of the aforementioned challenges of Web-based learning. A-WBLEs do so by providing mechanisms to individualize instruction (e.g., content, interface, strategies, and assessment) for online learners based on their individual differences (Inan \& Grant, 2008). A-WBLEs address individual differences by providing students with a more personal experience through the incorporation of various instructional strategies, resources, assessments, and interfaces. As a general outline, an adaptive web based learning system (1) gathers user information and preferences (Park \& Lee, 2003; Triantafillou, Pomportsis, \& Demetriadis, 2003); (2) builds a user model based on the learner's preferences, prior knowledge, skills and attitudes (Brusilovsky, 1998; Park \& Lee, 2003); (3) makes inferences based on the collected data and employs adaptive methods to accommodate each individual based on the developed user model (Danielson, 1997; Far \& Hashimoto, 2000; Inan \& Grant, 2008); and (4) continuously monitors the user's actions, errors, navigation, and learning process in order to update the user model depending on the collected and monitored data (Papanikolaou, Grigoriadou, Kornilakis, \& Magoulas, 2003). Figure 1 illustrates the basic architecture of an AWBLE. 


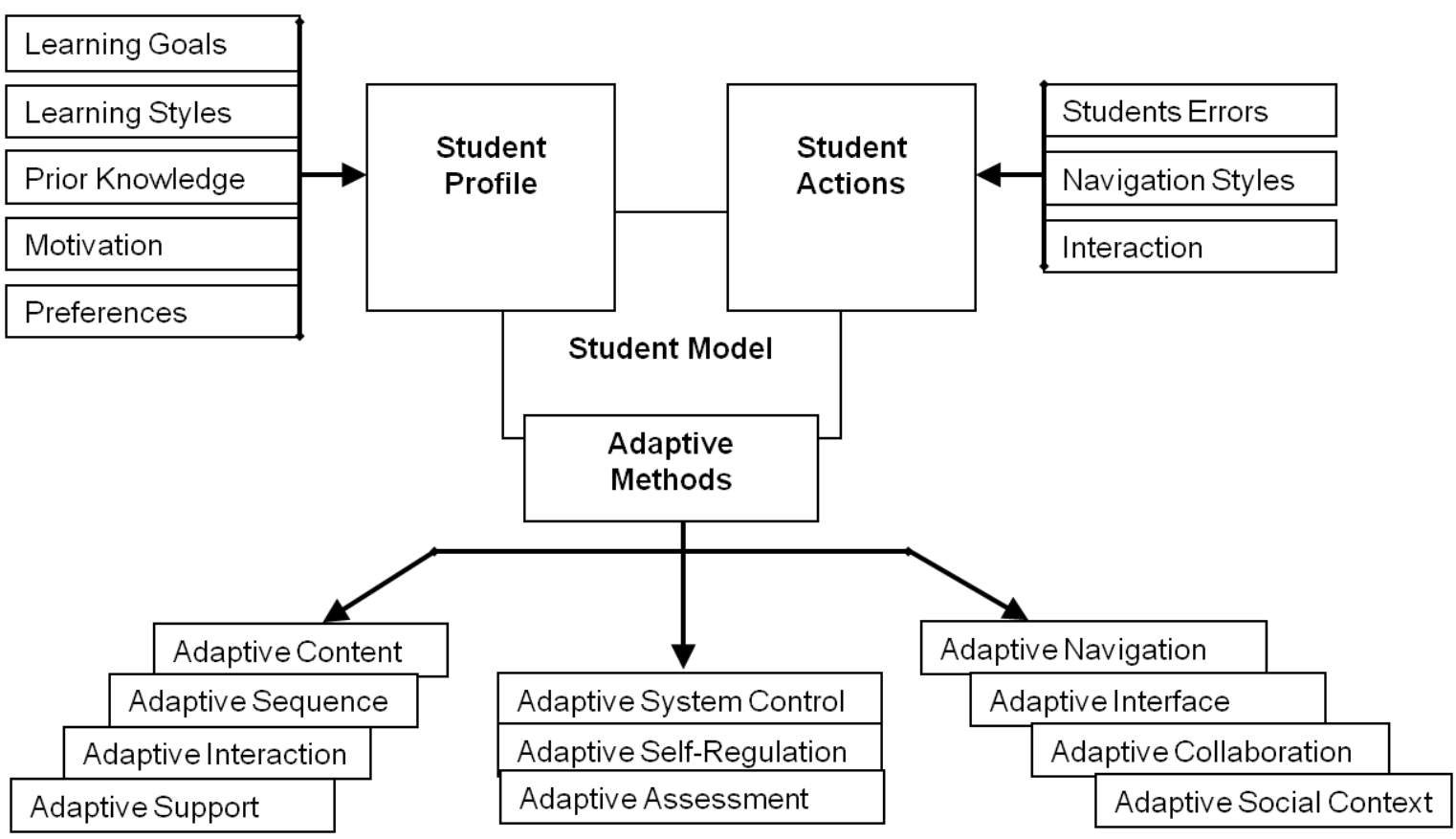

Figure 1 The architecture of an A-WBLE

\section{Adaptive Methods}

Adaptive methods are techniques, treatments, and strategies used by A-WBLEs to make adjustments and variations to Web-based instructional system' components in order to more fully accommodate individual differences (e.g., instructional needs, background, knowledge, and preferences) (Brusilovsky 1998, Inan \& Grant, 2008). There are several common adaptive methods used by early adaptive systems (Brusilovsky, 1998, 2001). These include such things as adaptive interfaces, content, and navigation. Inan and Grant (2008) propose a broad range of additional adaptive methods such as adaptive interaction, support, collaboration, social context, and assessment which can be used to improve many educational facets of adaptive Web-based instruction. Recently, adaptive self-regulation and learner control strategies have also been suggested to help students regulate their own learning in web-based learning environments (Azevedo, Cromley, Seibert, 2004; Azevedo, Moos, Greene, Winters, \& Cromley, 2008). In the following section, adaptive technologies have been briefly discussed (extensive discussion of adaptive methods can be found in Brusilovsky (2001) and Inan and Grant (2008)).

\section{Content Presentation}

Content presentation relates to the best way of presenting content (e.g., amount, difficulty, sequence, resources, etc) based on a learner's goals, prior knowledge, and other personal information. Adaptive content incorporates the use of strategies to modify the organization, format, and/or the amount of content (Brusilovsky, 2001; De Bra, Brusilovsky, \& Houben, 1999). Additionally, adaptive sequencing, which involves the effective ordering of content, can be used to ensure that students acquire the intended knowledge or skills to be taught (Brusilovsky, 2003). 


\section{Instructional Activities}

Adaptive instructional activities include instructional approaches to support learners and to increase their engagement in the learning process. Adaptive support involves providing individualized help, tailored to student needs, during the learning process (Brusilovsky, 2003; Far \& Hashimoto, 2000; Inan \& Grant, 2008). This also includes providing timely feedback in response to student actions. Adaptive communication, another form of adaptive instructional activity, involves adjusting interaction type so that it is more compatible to the user model (Inan \& Grant, 2008; Sabry \& Baldwin, 2003). Other adaptive instructional activities include adaptive collaboration which allows for the formation of matching collaboration groups by using system knowledge about individual users (Brusilovsky, 1999).

\section{Learning Environment}

A learning environment's usability, accessibility, and climate help students develop a more positive attitude towards the system (Dabbagh \& Bannan-Ritland, 2005; Inan, Yildirim, \& Kiraz, 2004). One way to instill a more positive attitude for a system is to incorporate an adaptive interface. With an adaptive interface, the visual appearance of the system (e.g., color, font style) can be altered to better suit individual preferences (Inan \& Grant, 2008). Adaptive navigation can also be used. This supports learner orientation in the online environment by changing the appearance and structure of navigations (Brusilovsky, 2003). Lastly, adaptive social context can be employed to provide an adjusted social context and activities. Adaptive social context have been reported to help maintain user interest and user appeal (Inan \& Grant, 2008).

\section{Student Assessment}

Assessment structure and content can also be adapted. Adaptive assessments provide learners with exposure to different types of learning tasks and problems (e.g., quizzes, product development, or group work) (Muir, 2001; Inan \& Grant, 2008). Additionally, adaptive assessments can be used to target and remedy weaker skills (Inan \& Grant, 2004).

\section{Learner Control}

Learner control techniques provide learners with the opportunity to control and manage their learning strategies, progress, and to manage and structure their learning environment. Adaptive system control gives each learner the option of setting system adaptation level and adaptive methods, individually or cooperatively (Inan \& Grant, 2008). Adaptive self-regulatory strategies help students plan, monitor, and evaluate their own learning in web-based learning environment (Azevedo, Moos, Greene, Winters, \& Cromley, 2008). 


\section{Empirical Evaluations of A-Wbles}

Although several adaptive web based systems have been developed, very few empirical studies have been conducted to prove the effectiveness of these systems and their impact on student performance, learning time, motivation, self-regulation, and attitudes. Further, common limitations of most available studies include short duration of time for treatments and small sample sizes. These existing empirical studies on adaptive systems can generally be categorized into three dimensions (Inan \& Grant, 2006; Papanikolaou \& Grigoriadou, 2004):

- Matching/mismatching instructional approaches with individual differences (Bajraktarevic, Hall, \& Fullick, 2003; Ford \& Chen, 2000, 2001; Gauss \& Urbas, 2003; Mitchell, Chen, \& Macredie, 2004);

- Testing the effectiveness of individual adaptive methods (Azevedo, Moos, Greene, Winters, \& Cromley, 2008; Brusilovsky, 2003; Brusilovsky, Sosnovsky, \& Shcherbinina, 2004; Gouli, Gogoulou, Papanikolaou, \& Grigoriadou, 2004; Graff, 2003); and

- Evaluating performance, learning time, and perceptions of students in adaptive hypermedia learning environment (Papanikolaou, Grigoriadou, Kornilakis, \& Magoulas, 2003; Triantafillou, Pomportsis, \& Demetriadis, 2003; Triantafillou, Pomportsis, Demetriadis, \& Georgiadou, 2004).

\section{Matching/Mismatching}

Matching and mismatching studies indicate that students perform better in matching situations in which instructional treatments are designed to meet the individual characteristics. For example, Ford and Chen (2001) explored the relationship between matching and mismatching instructional presentations according to students' cognitive styles. These researchers found significant differences between the performance of students on matched versus mismatched conditions. Further, they found that matching cognitive style to instructional presentation mainly affected male students. Similarly, Bajraktarevic, Hall, and Fullick (2003) found that students perform higher in recall test when hypermedia material is adapted to their learning style.

\section{Effectiveness of Individual Adaptive Methods}

Evaluations of the various components of the adaptive methods indicate mixed results. Content presentation and sequencing, adaptive self regulation, and adaptive assessment and feedback were found to increase student learning. Graff (2003) examined how segmenting content and providing an overview facilitate learning performance of students with different cognitive styles. He found that segmentation of content had an effect on the performance of students with different cognitive styles. Regarding the selection of content, Kelly and Tangney (2004) assigned 18 students with an average age of 13 years old into two groups. The first group received the adaptive version of learning environment and other group used the free choice version. The results indicated that learning increased when students did not get their preferred learning resources.

A series of studies indicated that those students who take adaptive scaffold for self-regulation strategies demonstrated better learning performance over the group who take a fixed or no 
scaffolding for self-regulation (Azevedo, Moos, Greene, Winters, \& Cromley, 2008; Azevedo, Winters, \& Moos, 2004). Similarly, Brusilovsky, Sosnovsky, and Shcherbinina (2004) found that students cover more questions and perform better in adaptive self evaluation quiz systems with adaptive navigation. Another study by Gouli, Gogoulou, Papanikolaou, and Grigoriadou (2004) examined the effects of providing adaptive feedback based on the student knowledge and preferences. The findings from that study indicated that adaptive feedback schemes support students' learning and help them to identify and correct their errors.

On the other hand, studies did not find significant effects with adaptive navigation and interface. For example, Brusilovsky (2003) examined adaptive navigation on 25 undergraduate preservice teachers. Although students with differing levels of prior knowledge appreciated different adaptive navigation techniques, these adaptations did not have a significant effect on their final achievement scores. However, having a virtual character personalize the interaction with the user through the use of a particular links recommender system did have a positive impact on the users' perception of the system as a learning tool (Reategui, Boff, \& Campbell, 2008).

\section{Evaluation of Performance, Learning Time, and Perceptions}

One of few comprehensive empirical evaluations of adaptive web based learning system was conducted by Triantafillou, Pomportsis, Demetriadis, and Georgiadou (2004). These researchers measured student achievement scores and attitudes in an adaptive hypermedia system on which adaptations were made based on the students' cognitive styles. The findings indicated that students in experiment groups performed better than the control group. A similar study by Papanikolaou, Grigoriadou, Kornilakis, and Magoulas (2003) evaluation showed that students, overall, were satisfied with the adaptive system. Also, they observed that students with different learning styles concentrated on different types of knowledge modules and followed dissimilar patterns to accomplish learning task. In both studies, however, students indicated that they preferred to have control, as opposed to being controlled by the system.

\section{Categorizing A-WBLEs}

There are many types of adaptive web based learning environments. These varieties result from the (1) broadness of A-WBLEs which differ based on the individual traits considered, (2) approaches for creating and updating user models, or the (3) applications of differing adaptive methods. These massive differences make it difficult for one to understand, implement, and evaluate adaptive systems. We suggest four levels of adaptation: Pseudo, Naïve, Advanced, and Ultimate. These levels were created by considering how the system judges individual traits, how the user model was created and which types of adaptive methods were used.

\section{Level - 1: Pseudo A-WBLE}

This level is a base level for adaptation. In this level there is no development of user model or any application of adaptive methods. Basically, individual differences are accommodated by providing many formats of instructional material with different mediums (Ford, \& Chen, 2001; Inan, Yildirim, Kiraz, 2004). Users are expected to benefit from materials by their own 
individual preference. These systems are not personalized but rather are designed to compensate for individual differences by providing multiple options.

\section{Level - 2: Naive A-WBLE}

Personalization starts in this level. Each individual has different treatments by application of adaptive methods. These adaptive instructional treatments and variables accounting for individual differences were very limited in number. Basically, the system has only one adaptive method (e.g., content presentation) matched to one individual difference variable (e.g., learning style). This level of adaptive systems is used commonly for supportive purposes such as adaptive testing (Brusilovsky, Sosnovsky, \& Shcherbinina, 2004).

\section{Level - 3: Advanced A-WBLE}

Most A-WBLEs fall into this level (Aroyo, De Bra, Houben, \& Vdovjak, 2004; Papanikolaou, Grigoriadou, Kornilakis, \& Magoulas, 2003). This level of the adaptive system includes a few essential individual variables to apply common adaptive methods. However, most of the adaptations occur with the interface, content and navigation of the system. Further, some of these systems have not been fully developed to monitor student progress and their action to update user models.

\section{Level - 4: Ultimate A-WBLE}

This level characterizes the next generation of adaptive systems. It includes all of the necessary individual difference variables and applies all the necessary adaptive methods to accommodate individual differences. The user model is completely dynamic and is updated continuously by monitoring student action, progress, and errors. The system functions are adaptable; allowing updates to the system itself without outside coding etc. Furthermore, emergent technologies and methods for assessing student emotional states and eye tracking are used.

\section{Conclusion}

Adaptive Web-Based Learning Environments (A-WBLEs) are a form of online instruction which attempt to remedy the challenges of Web-based learning by addressing individual differences. A-WBLEs use various adaptive methods for individualizing content presentation, instructional activities, learning environments, student assessments; and varying the level of learner control. These systems differ on the individual traits for which they adapt for, approaches for creating and updating user models, and/or the applications of differing adaptive methods. The levels of adaptation also vary from no adaptation (with pseudo A-WBLEs) to full adaptation (with ultimate A-WBLEs). While A-WBLEs continue to be developed, designers should strive to go beyond the Level -1 and 2 categories; and aim for the more mature Level- 3 and 4 .

As the number of adaptive systems and initiatives increase, there is a strong need for more empirical studies to test many aspects of A-WBLE design. Recommendations for future studies include, first and foremost, further examination of individual differences and their impact on 
student learning. Although there are numerous studies already in existence, there is need for future studies to focus their attention and investigation towards the identification of key variables which affect student learning and the extent of their impact. Because there are so many learner characteristics that can be adapted for, it is crucial to discover which are the most important and to focus future adaptability efforts on these variables. Secondly, there is a need for empirical studies to examine the effectiveness of full or partial applications of adaptive techniques on student learning. In other words, research should investigate how much adaptation is needed to build efficient systems which yield optimal learning results. Thirdly, future studies should explore differences in students' learning strategies in the hypermedia environment. Future adaptive systems may possibly provide tools such as highlights, bookmarking, and note-taking tools to support students' learning strategies. Lastly, future studies should investigate student attitudes, competency, satisfaction and readiness to use an adaptive system.

\section{References}

Allen, I. E. \& Seman, J. (2004). Entering the mainstream: The quality and extend of online education in the United States, 2003 and 2004. Nedham, MA: The Sloan Consortium.

Allen, I. E. \& Seman, J. (2008). Online notion: Five years of growth in online learning. Nedham, MA: The Sloan Consortium.

Aroyo, L., De Bra, P., Houben, G., \& Vdovjak, R. (2004). Embedding information retrieval in adaptive hypermedia: IR meets AHA! New Review of Hypermedia and Multimedia, 10(1), 53-76.

Azevedo, R., Cromley, J. G., \& Seibert, D. (2004). Does adaptive scaffolding facilitate students' ability to regulate their learning with hypermedia? Contemporary Educational Psychology, 29(3), 344-370.

Azevedo, R., Moos, D. C., Greene, J. A., Winters, F. A., \& Cromley, J. G. (2008). Why is externally-facilitated regulated learning more effective than self-regulated learning with hypermedia? Educational Technology Research and Development, 56(1), 45-72.

Berge, Z. L. (2002). Active, interactive, and reflective eLearning. Quarterly Review of Distance Education, 3(2), 181-190.

Bajraktarevic, N., Hall, W., \& Fullick, P. (2003). Incorporating learning styles in hypermedia environment: Empirical evaluation. Paper presented at the Adaptive Hypermedia and Adaptive Web-Based Systems Workshop, Budapest, Hungary.

Brusilovsky, P. (1998). Adaptive educational systems on the World-Wide-Web: A Review of available technologies. Paper presented at the International Conference in Intelligent Tutoring Systems, San Antonio, TX.

Brusilovsky, P. (1999). Adaptive and intelligent technologies for Web-based education. Künstliche Intelligenz, 4, 19-25.

Brusilovsky, P. (2001). Adaptive hypermedia. User Modeling and User-Adapted Interaction, 11(1/2), 87-110.

Brusilovsky, P. (2003). Adaptive navigation support in educational hypermedia: The role of student knowledge level and the case for meta-adaptation. British Journal of Educational Technology, 34(4), 487-497. 
Brusilovsky, P., Sosnovsky, S., \& Shcherbinina, O. (2004). QuizGuide: Increasing the educational value of individualized self-assessment quizzes with adaptive navigation support. Proceeding of the World Conference on E-Learning in Corp., Govt., Health., \& Higher Ed., 2004(1), 1806-1813.

Chen, S. Y. \& Paul, R. J. (2003). Editorial: Individual differences in web-based instruction-an overview. British Journal of Educational Technology, 34(4), 385-392.

Dabbagh, N., \& Bannan-Ritland, B. (2005). Online learning: Concept, strategies, and applications. Upper Saddle River, NJ: Pearson Education.

Danielson, R. L. (1997, June). Work in progress: Learning styles, media preferences, and adaptive education. Paper presented at the Adaptive Systems and User Modeling on the World Wide Web Workshop, Chia Laguna, Sardinia.

De Bra, P. (2000). Pros and cons of adaptive hypermedia in Web-based education. CyberPsychology and Behavior, 3(1), 71-77.

De Bra, P., Brusilovsky, P., \& Houben, G. (1999). Adaptive hypermedia: From system to framework. ACM Computing Survey, 31(4).

Dutton, J., Dutton, M., \& Perry, J. (2002), How Do Online Students Differ From Lecture Students? Journal of Asynchronous Learning Networks, 6(1).

Far, B. H. \& Hashimoto, A. H. (2000). A Computational model for learner's motivation states in individualized tutoring system. Paper presented at the International Conference on Computer Assisted Instruction, Taipei, Taiwan.

Ford, N. \& Chen, S. Y. (2000). Individual differences, hypermedia navigation, and learning: An empirical study. Journal of Educational Multimedia and Hypermedia, 9(4), 281-311.

Ford, N. \& Chen, S. Y. (2001). Matching/mismatching revisited: An empirical study of learning and teaching styles. British Journal of Educational Technology, 32(1), 5-22.

Gauss, B. \& Urbas, L. (2003). Individual differences in navigation between sharable content objects-an evaluation study of a learning module prototype. British Journal of Educational Technology, 34(4), 499-509.

Gouli, E., Gogoulou, A., Papanikolaou, K., \& Grigoriadou, M. (2004). Designing an adaptive feedback scheme to support reflection in concept mapping. Paper presented at the Proceedings of the Adaptive Hypermedia 2004 Workshop, The Nederlands.

Graff, M. (2003). Learning from Web-based instructional systems and cognitive style. British Journal of Educational Technology, 34(4), 407-418.

Gunawardena, C.N. \& Mclsaac, M. S. (2003). Distance education. In D.H. Jonassen (Ed.), Handbook of Research on Educational Communications and Technology, 2nd Edition. (pp. 113-142). Mahwah, NJ: Lawrence Erlbaum Associates, Inc.

Hannafin, M. J., Hill, J. R., \& Land, S. M. (1997). Student-centered learning and interactive multimedia: Status, issues, and implications. Contemporary Education, 68(2), 94-97.

Hill, J. R. \& Hannafin, M. J. (2001). Teaching and learning in digital environments: The resurgence of resource-based learning. Educational Technology Research \& Development, 49(3), 37-52. 
Inan, F. A. \& Grant, M. M. (2004). Applications of adaptive technologies in online learning. Proceeding of the World Conference on E-Learning in Corp., Govt., Health., \& Higher Ed., 2004(1), 2701-2706.

Inan, F. A. \& Grant, M. M (2006, October). Adaptive Web Based Learning Environment (AWBLE): Synthesis of Empirical Evaluations and Conditions for Successful Adaptive Web Based System Implementation. Paper presented at the Annual Convention of the Association for Educational Communications and Technology, Dallas, TX.

Inan, F. A. \& Grant, M.M. (2008). Individualized web-based instructional design. In Kidd, T. T., \& Song, H. (Eds). Handbook of Research on Instructional Systems and Technology. Harrisburg, PA: Idea Group Publishing.

Inan, F. A. \& Lowther, D. L. (2007). Comparative analysis of computer-supported learning models and guidelines. In H. F. M. Neto \& F. V. Brasileiro (Eds.), Advances in computersupported learning. Harrisburg, PA: Idea Group Publishing.

Inan, F. A. Yildirim, S., \& Kiraz, E. (2004). A design and development of an online learning support system (OLSS) for preservice teachers: A discussion of attitudes and utilization. Journal of Interactive Instruction Development, 17(4), 1-15.

Khan, B. H. (1997). Web-based instruction. Englewood Cliffs, NJ: Educational Technology Publications.

Kelly, D. \& Tangney, B. (2004). Evaluating presentation strategy and choice in an adaptive multiple intelligence based tutoring system. Paper presented at the Adaptive Hypermedia 2004 Workshop, The Nederlands.

McGrath, B. (1998). Partners in learning: twelve ways technology changes the teacher-student relationship. T.H.E. Journal, 25(9), 58-61.

Mitchell, T., Chen, S. Y., \& Macredie, R. (2004). Adapting hypermedia to cognitive styles: Is it necessary? Paper presented at the Adaptive Hypermedia 2004 Workshop, The Nederlands.

Moore, M. G. \& Kearsley, G. (1996). Distance education: A systems view: Wadsworth Publishing Company.

Muir, D. J. (2001). Adapting online education to different learning styles. Paper presented at the National Educational Computing Conference, Chicago, IL.

O'Brien, B. \& Renner, A.L. (2002). Online Student Retention: Can It Be Done? World Conference on Educational Multimedia, Hypermedia and Telecommunications, 2002(1), 1479-1483.

Papanikolaou, K. A. \& Grigoriadou, M. (2004). Accomodating learning style characteristics in adaptive educational hypermedia systems. Paper presented at the Proceedings of the Adaptive Hypermedia 2004 Workshop, The Nederlands.

Papanikolaou, K. A., Grigoriadou, M., Kornilakis, H., \& Magoulas, G. D. (2003). Personalizing the interaction in a Web-based educational hypermedia system: The case of INSPIRE. User Modeling and User-Adapted Interaction, 13(3), 213-267.

Park, O. \& Lee, J. (2003). Adaptive instructional system. In D. H. Jonassen (Ed.), Handbook of research for educational communications and technology (pp. 403-437). Mahwah, NJ: Lawrence Erbaum Associates.

Parker, A. (1995). Distance education attrition. International Journal of Educational Telecommunications, 1(4), 389-406. 
Picciano, A. G. (2001). Distance learning: Making connections across virtual space and time. Upper Saddle River, NJ: Prentice-Hall.

Reategui, E., Boff, E., \& Campbell, J. A. (2008). Personalization in an interactive learning environment through a virtual character. Computers \& Education 51, 530-544.

Saba, F. (2002). Student attritions: How to keep your online learner focused. Distance Education Report, 14(4), 1-2.

Sabry, K. \& Baldwin, L. (2003). Web-based learning interaction and learning styles. British Journal of Educational Technology, 34(4), 443-454.

Schrum, L. \& Benson, A. (2001). Establishing successful online distance learning environment: Distinguishing factors that contribute to online courses and programs. In R. Discenza, C. Howard \& K. Schenk (Eds.), The design and management of effective distance learning programs. Hershey Pa.: Idea Group Publishing.

Setzer, J. C. \& Lewis, L. (2005). Distance education courses for public elementary and secondary school students: 2002-03 (NCES 2005-010). U.S. Department of Education. Washington, DC: National Center for Education Statistics.

Sikora, A. C. \& Carroll, C. D. (2003). A profile of participation in distance education: 1999-2000 (No. NCES 2003-154). Washington, DC: National Center for Educational Statistics.

Song, L., Singleton, S. E., Hill, J. R. \& Koh, M. H. (2004). Improving online learning: Student perceptions of useful and challenging characteristics. Internet and Higher Education, 7(1), 59-70.

Terry, N. (2001). Assessing enrollment and attrition rates for the online MBA. T.H.E. Journal, 28(7), 64-68.

Triantafillou, E., Pomportsis, A., \& Demetriadis, S. (2003). The design and the formative evaluation of an adaptive educational system based on cognitive styles. Computers \& Education, 41(1), 87- 103.

Triantafillou, E., Pomportsis, A., Demetriadis, S., \& Georgiadou, E. (2004). The value of adaptivity based on cognitive style: an empirical study. British Journal of Educational Technology, 35(1), 95-106.

Vergidis, D. \& Panagiotakopoulos, C. (2002). Student dropout at the Hellenic Open University: Evaluation of the graduate program, "Studies in Education". International Review of Research in Open and Distance Learning, 3(2).

Vonderwell, S. (2003). An examination of asynchronous communication experiences and perspectives of students in an online course: A case study. Internet and Higher Education, 6, 77-90.

Xenos, M., Pierrakeas, C., \& Pintelas, P. (2002). A survey on student dropout rates and dropout causes concerning the students in the course of informatics of the Hellenic Open University. Computers \& Education, 39(4), 361-377.

Yukselturk, E. \& Inan, F. A. (2006). Examining the factors affecting student dropout in an online learning environment. Turkish Online Journal of Distance Education, 7(2).

Zheng, L. \& Smaldino, S. (2003). Key instructional design elements for distance education. Quarterly Review of Distance Education, 4(2), 153-166. 
Correspondence: Fethi A. Inan, Assistant Professor, College of Education, Room \#267, Box 41071, Texas Tech University, Lubbock, TX 79409, United States 